\title{
Isolamento e Preservação de Local de Crime - Procedimento Substancial à Integridade do trabalho Pericial
}

\author{
A.M. Silveira ${ }^{\mathrm{a},},{ }^{*}$ A. Pereira ${ }^{\mathrm{b}}$ \\ ${ }^{a}$ Universidade Adventista de São Paulo - UNASP, São Paulo (SP), Brasil \\ ${ }^{b}$ Instituto de Criminalística, Superintendência de Polícia Técnico-Científica, São Paulo (SP), Brasil \\ *Endereço de e-mail para correspondência: andreiaejp@hotmail.com. \\ Recebido em 21/01/2019; Revisado em 24/04/2020; Aceito em 02/06/2020
}

\begin{abstract}
Resumo
O presente documento trata-se de uma revisão teórica dos parâmetros fáticos, científicos e políticos relativos ao isolamento e a preservação de local do crime, com objetivo de manter a integridade da prova material. Dentro desse contexto, este trabalho propõe se apresentar através de revisão bibliográfica, em que as plataformas pesquisadas consistiram na literatura disponível, bem como na legislação vigente, de forma a nortear os agentes do Estado com a finalidade de atender à sociedade. Foram consideradas, para este estudo, somente as publicações correlatas ao período de 1940 a 2019 e que acompanharam a evolução deste através do tempo. A importante necessidade de tornar acessível os conhecimentos técnicos científicos relacionados à criminalística. Este artigo reflete, essencialmente, questões relacionadas à segurança jurídica da atividade pericial; aspectos conflitivos dos demais agentes envolvidos nas diligências em locais de crime; o papel da sociedade frente ao crime e aos respectivos reflexos no curso do trabalho pericial. Frente a problemática apresentada, conclui-se pela ação gradativa do conhecimento científico, assim como já acontece na esfera do direito.
\end{abstract}

Palavras-Chave: Pesquisa bibliográfica; Integridade da prova material; Conhecimento técnico; Segurança Jurídica da atividade pericial.

\begin{abstract}
This document concerns to a theoretical review of the phatic, scientific and political parameters related to the isolation and the preservation of the crime scene, in order to maintain the integrity of the material evidence. In this context, this work proposes to present itself through bibliographic review, whose the researched platforms had consisted of available literature, as well as the current legislation, to offer guidance to the agents of the State, with the purpose of serving society. Were considered, for this study, only publications related to the period from 1940 to 2019 and which followed the evolution of the same through the time. The important need of making the scientific technical knowledge related to the criminalistics accessibility. This article reflects, essentially, affairs related to legal security on scientific expertise; conflicting aspects of the other agents involved on the diligences in crime scenes; the society role in the face of the crime and to the respective consequences in the course of experts work. Based on the presented problem, it is concluded by the gradual action of scientific knowledge, as it has already occurs in the sphere of law.
\end{abstract}

Keywords: Bibliographic research; integrity of the material evidence; technical knowledge; concerning legal security on scientific expertise.

\section{INTRODUÇÃ̃O}

Este trabalho - na área do conhecimento criminalístico - busca identificar conflitos e contribuições à cerca do tema: idoneidade material da prova no local do crime. No contexto ao qual está inserido, pode-se destacar que é um assunto atual, visto que, apresenta conflitos, dados critérios subjetivos que o cercam.

Hoje, no Brasil, ainda há uma grande deficiência com a sistemática do fato que, por conseguinte, vem a prejudicar 
à ação dos Peritos Criminais. A finalidade principal é a integridade da prova, ou seja, que não se alterem os vestígios deixados pelos envolvidos, assim como, que não venha a ser acrescido nenhum outro elemento material que não tenha relação com o crime pelos socorristas ou mesmo por curiosos.

Apesar do agente que faz a preservação de local, receber os conhecimentos básicos, em muitos casos, este não o aplica, contudo, em 2004, MEROTTI realizou uma pesquisa com 589 Soldados e 267 Sargentos recémformados, em que já se demonstrava o acesso as informações aos agentes policiais.

Do total dos participantes da pesquisa, 524 (89\%) soldados e $267(100 \%)$ sargentos responderam de forma afirmativa que teve na grade curricular do seu curso de formação o assunto preservação de local de crime, sendo que este assunto se encontrava inserido na disciplina de criminalística.

Duas tabelas do referido estudo fornecem dados à cerca da importância do exame pericial e sobre o esclarecimento da correta preservação.

Tabela 1. Quanto a importância do exame pericial e a graduação do militar.

\begin{tabular}{l|c|c|c|c}
\hline \multirow{2}{*}{ Importância do exame pericial } & \multicolumn{2}{|c|}{ Soldados } & \multicolumn{2}{c}{ Sargentos } \\
\cline { 2 - 5 } Nenhuma & $\mathrm{N}$ & $\%$ & $\mathrm{~N}$ & $\%$ \\
Pouco importante & 0 & $0,0 \%$ & 0 & $0,0 \%$ \\
Razoavelmente importante & 0 & $0,0 \%$ & 0 & $0,0 \%$ \\
Importante & 0 & $0,0 \%$ & 0 & $0,0 \%$ \\
Muito importante & 27 & $4,6 \%$ & 10 & $3,7 \%$ \\
Não respondidas & 560 & $95,1 \%$ & 257 & $96,3 \%$ \\
\hline Total & 2 & $0,3 \%$ & 0 & $0,0 \%$ \\
\hline
\end{tabular}

A tabela 1 destaca praticamente unanimidade em relação à importância do exame pericial, denotando que os militares são conscientes do valor do exame pericial no auxílio à elucidação de um crime.

Tabela 2. Quanto ao esclarecimento de um crime quanto à correta preservação do local de crime segundo a graduação do militar.

\begin{tabular}{l|c|c|c|c}
\hline \multirow{2}{*}{ O esclarecimento de um caso policial (crime) } & \multicolumn{2}{|c|}{ Soldados } & \multicolumn{2}{|c}{ Sargentos } \\
\cline { 2 - 5 } depende de correta preservação do local de crime & $\mathrm{N}$ & $\%$ & $\mathrm{~N}$ & $\%$ \\
Nem sempre & 39 & $6,6 \%$ & 25 & $9,4 \%$ \\
Não & 0 & $0,0 \%$ & 1 & $0,4 \%$ \\
Sempre & 430 & $73,0 \%$ & 179 & $67,0 \%$ \\
Depende do crime & 116 & $19,7 \%$ & 58 & $21,7 \%$ \\
Não respondidas & 4 & $0,7 \%$ & 4 & $1,5 \%$ \\
\hline Total & 589 & $100 \%$ & 267 & $100 \%$
\end{tabular}

A tabela 2 refere que $73 \%$ dos soldados e $67,0 \%$ dos sargentos afirmam que sempre o esclarecimento de um crime depende de uma correta preservação do local; 19,7\% dos soldados e $21,7 \%$ dos sargentos acham que depende do crime e $6,6 \%$ dos soldados e $9,4 \%$ dos sargentos acredita que, nem sempre, um delito pode ser esclarecido devido à correta preservação do local de crime
Segundo VELHO (2013) “Geralmente pensa-se em perícia para encontrar as provas materiais que sirvam para incriminar os culpados, o que é verdadeiro, porém o foco da perícia é analisar os elementos materiais com vistas a desvendar o que aconteceu". Assim sendo, conclui-se que o trabalho pericial é exercido com o introito de se chegar às verdades de fato.

A relevância da preservação do local de crime tem se tornado prioridade dentro da investigação policial, visto que se trata de um ambiente rico em evidências, que juntas compõe a base para execução de um laudo pericial integro.

Diante dessas informações, este estudo vem com a finalidade de questionar acerca de quais são os principais erros cometidos durante o isolamento e a preservação do local do crime, assim como suas consequências, insuperáveis, advindas de práticas inadequadas. Apresentar a todos os envolvidos em uma cena de crime - desde os agentes representantes do Estado, assim como aos particulares - sugestões de como proceder em um local de crime, com base padronização procedimental, a ser implementada pelo Estado, responsáveis pela investigação Policial.

\section{METODOLOGIA}

O estudo compõe uma revisão bibliográfica, em que foram utilizados livros impressos, eletrônicos e legislação vigente, além de artigos selecionados nos seguintes bancos de dados: Ministério da Justiça, Secretaria Nacional da Segurança Pública, Scielo, PubMed, Periódico Capes e Google Acadêmico. Para a pesquisa nestes bancos, foram utilizadas as seguintes palavras chave: Integridade da prova material; Conhecimento técnico; Segurança Jurídica da atividade pericial., isolamento e preservação de locais de crime. Para os critérios de seleção, foram escolhidas publicações entre o período de 1940 a 2019, com idioma em português, em que os conceitos deste trabalho, eram explícitos.

\section{LOCAL DE CRIME}

Para RABELLO (1996) "Local de Crime - é a porção do espaço compreendida num raio que, tendo por origem o ponto no qual é constatado o fato, se estenda de modo a abranger todos os lugares em que, aparente, necessária ou presumivelmente, hajam sido praticados, pelo criminoso, ou criminosos, os atos materiais, preliminares ou posteriores à consumação do delito e com estes diretamente relacionados". Com base neste entendimento, conclui-se que local de crime se trata de uma área física que abranja a totalidade dos indícios. A relação completa desses espaços farão com que se possa coletar uma maior quantidade de vestígios disponíveis, tornando a laudo pericial mais completo possível. 
Doutrinariamente, as áreas de local de crime dividemse em áreas imediata, mediata e relacionada. Sendo a primeira, local onde ocorreu o fato delituoso; a área mediata é toda aquela adjacente ao fato; a área relacionada tem como característica o isolamento das demais, contudo, está pode fornecer dados relevantes para condução do caso.

KEHDY (1968) define que "local de crime é toda área onde tenha ocorrido qualquer fato que reclame as providencias da polícia".

Com base no Código de Processo Penal (CPP): Artigo $6^{\circ}$, "Logo que tiver conhecimento da prática da infração penal, a autoridade policial deverá: Dirigir-se ao local, providenciando para que não se alterem o estado de conservação das coisas, até a chegada dos peritos", do Código de Processo Penal - CPP.

Neste artigo $6^{\circ}$ há de se esclarecer dois pontos principais:

O primeiro, trata-se do termo autoridade policial, neste contexto deve-se entender como o delegado de polícia titular do Inquérito Polícia - Não obstante, no âmbito de Isolamento e preservação de local de crime, essa obrigatoriedade recai a qualquer agente do Estado que acompanhar a ocorrência.

Para o ordenamento jurídico brasileiro, o local do crime apresenta três teorias:

$1^{a}$ Teoria da Ação - lugar do crime é aquele a ação foi praticada (ou omissão);

$2^{\text {a }}$ Teoria do Resultado - o lugar do crime é aquele em que se deu o resultado;

$3^{\text {a }}$ Teoria Mista - ou da Ubiquidade, esta teoria trata-se da junção da teoria da ação e do resultado e é utilizada hoje no ordenamento jurídico brasileiro.

Destaca MALLMITH (2007) que: "O grupo de policiais - civis, militares, peritos, delegados etc. - estão no local do crime por delegação estatal, na condição de representantes do Estado, para que os procedimentos que forem implementados na cena, obedeçam aos parâmetros legais".

O segundo ponto a ser analisado é o termo infração penal - esta que é gênero de toda conduta previamente tipificada pela legislação como ilícita. Neste estudo, abordaremos o termo "crime" de forma ampla, com base no seu critério material ou substancial.

De acordo com esse critério, Segundo MASSON (2014) "crime é toda ação ou omissão humana que lesa ou expõe a perigo de lesão bens jurídicos penalmente tutelado".

No tocante ao exame em local de crime, sua indispensabilidade é tratada no artigo 158 do mesmo código: Artigo 158." Quando a infração deixar vestígios, será indispensável o exame de corpo de delito, direto ou indireto, não podendo supri-lo a confissão do acusado.

É fato e bem observado por Velho (2013) que: “Ter uma perícia eficaz e eficiente é, portanto, uma garantia do indivíduo de que os processos penais serão conduzidos com base num suporte fático, rígido e científico que conduza a alegações verdadeiras e ao esclarecimento da verdade. Neste escopo a legislação brasileira impede que a defesa, a acusação e mesmo o juiz possam obstá-lo."

Neste sentido, observa-se que o estudo pericial vai além dos objetivos das partes, trazendo em seu bojo os fundamentos da República, atendendo à democracia, ao Estado de direito, à cidadania e a dignidade da pessoa humana.

Como bem define OLIVEIRA (2009) “Segurança é um serviço público a ser prestado pelo Estado. O cidadão é o destinatário desse serviço"

\section{1 isolamento e preservação}

Com base no Código de Processo Penal (CPP):

Art. 158-B, II - isolamento: ato de evitar que se altere o estado das coisas, devendo isolar e preservar o ambiente imediato, mediato e relacionado aos vestígios e local de crime.

Isolamento e preservação são dois termos similares, aos quais carregam características distintas. Contudo, pode-se definir isolamento como a restrição de acesso à determinado local de crime, e preservação como o ato de manter a guarda - vigilância - para que nada seja alterado. Diferente da limitação geográfica do isolamento, a qual enfrenta restrições quanto a sua totalidade, preservar é ato complexo que enfrenta problemas desde o acesso de curiosos, assim como, aqueles que dentro de suas atribuições policiais acreditam possuir autonomia para circular na área isolada.

Vigente no artigo 169 do CPP: "Para o efeito de exame do local onde houver sido praticada a infração, a autoridade providenciará imediatamente para que não se altere o estado das coisas até a chegada dos peritos, que poderão instruir seus laudos com fotografias, desenhos ou esquemas elucidativos. - Parágrafo único. Os peritos registrarão, no laudo, as alterações do estado das coisas e discutirão, no relatório, as consequências dessas alterações na dinâmica dos fatos."

Quanto à preservação do local de crime, emerge como ponto inicial do trabalho pericial a sua idoneidade. Quando classificado como local Inidôneo - não preservado conclui-se que os vestígios sofreram alguma alteração até a chegada dos peritos. Esta ação de mácula pode ocorrer por questões climáticas, temporais ou mesmo humana, neste segundo caso, a própria ação do homem, pode-se criar um novo vestígio; Se idôneo - preservado - oferece ao profissional amplo grau de segurança em suas análises; Quando prejudicado, determina, desde logo que não há campo para perícia, estando os vestígios irreversivelmente destruídos.

A preservação do local do crime constitui a garantia de idoneidade em relação a obtenção e análise de vestígios, os quais compõe uma base segura de prova material. Cada local de crime possui características próprias, as quais 
exigem do profissional pericial uma série de cuidados exclusivos, desde a sua preparação à organização dos trabalhos em campo. Durante o decorrer do exame pericial, os critérios de análise podem sofrer alterações conforme aferição de novos indícios que sejam reconhecidos. E cabe ao Perito Criminal se adaptar ao novo cenário.

A preservação do local de crime, assim como, o isolamento e demais cuidados com os vestígios é uma garantia de que o Perito encontrará a cena do crime segura - pertinente - com o que ocorreu de fato, devido à ação do infrator, assim, como pela vítima, tendo com isso, a possibilidade de analisar todos os vestígios com segurança.

Apesar de todo conhecimento adquirido por todos aqueles que detém a atribuição legal para preservar o local, há muitos pontos de discordância, isto porque, por descuido, ainda se perde importantes informações relevantes para desvendar crimes. Incontestável é que algumas modificações devem ser consideradas, não como elementos que alteram a cena do crime, mas como conjunto de informações que compõe os fatos. São exemplos os procedimentos de prestação de socorro, rompimento de obstáculos para salvamento entre outras ações necessárias.

Em curso temporal a preservação de local de crime ocorre em três períodos:

$1^{\circ}$ fase - da ocorrência da infração à chegado do primeiro agente de segurança;

$2^{\circ}$ fase - da chegada do primeiro agente à chegada da autoridade policial - delegado do polícia.

$3^{\circ}$ fase - da chegada da autoridade policial à chegada do Perito Criminal.

Analiticamente, a primeira fase da preservação é mais crítica, visto que em alguns casos a curiosidade dos presentes tendem a influir de maneira significativa de modo a trazer um prejuízo gravoso ao trabalho pericial. Neste momento também é feito o primeiro isolamento da área, o qual, um agente sem conhecimento pericial isola o local do crime, acreditando, atender à necessidade dos Peritos. Este isolamento - antes da perícia - muitas vezes não abrange todo a área necessária, consoante a falta de conhecimento analítico do agente que o define.

A segunda e a terceira fase apresentam características similares, visto que as preservações se mantêm, ligeiramente, similares. Contudo, é na terceira fase que o isolamento acontece de forma completa, pois com a chegada dos Peritos, estes, analisam a área e determinam um isolamento mais adequado, alterando, quando necessário. A Problemática acontece quando - por ineficácia do isolamento ou da preservação na primeira fase - o local torna-se inidôneo. É também neste momento que o próprio Perito faz uma avaliação prévia a fim verificar a necessidade de outros peritos especializados, tomando a devida cautela, para, ainda este, não prejudicar objeto material que deve ser analisado por outro perito.

Desse modo, ESPÍNDULA (2009), menciona que o local de crime idôneo é tido como aquele que estaria completamente intocável, de modo que seja preservado os seus vestígios, bem como mantidas todas as condições deixadas pelos agentes do delito, no caso a vítima e agressor.

A segurança do local de crime constitui a garantia de idoneidade em relação a obtenção e análise de vestígios, isso porque, é com a preservação do local do crime em que se dá início a cadeia de custódia - processo este, em que se documenta a história cronológica dos vestígios - os quais compõe uma base segura de prova material.

Segundo MARINONI (2009), " O perito traz ao processo análise técnica e científica de um sujeito dotado de idoneidade moral".

Cada local possui características próprias, as quais exigem do profissional pericial uma série de cuidados exclusivos, desde a sua preparação à organização dos trabalhos em campo. Durante o decorrer do exame pericial, os critérios de análise podem sofrer alterações conforme aferição de novos indícios que sejam reconhecidos e o Perito Criminal terá que se adaptar ao novo cenário.

No campo da segurança pública, fato é que faltam informações precisas que possam descrever as possíveis dinâmicas criminais, que inviabiliza, sistematicamente, a elaboração de um sistema de política global. Não havendo clareza quanto as metas, não é possível uma avaliação rigorosa.

Consoante ao Projeto de Segurança Pública Para o Brasil, acredita-se que a preservação de local de crime deve ser convertida em um princípio sagrado para atuação policial, válido para todos os agentes policiais envolvidos, dada sua extraordinária importância, e que a violação da rotina de preservação estabelecidas seja punida, administrativa ou criminalmente.

\subsection{Vestígios e Indícios}

Vestígios - como termo global - pode ser definido por qualquer elemento na cena do crime que esteja fora da normalidade.

Segundo Código de Processo Penal, art. 158A, §3, Vestígio é todo objeto ou material bruto, visível ou latente, constatado ou recolhido, que se relaciona à infração penal

Podendo ser classificados como: Macro; Micro; visíveis ou latentes, que precisam ser revelados. O perito criminal MALLMITH (2007), assim define vestígios: “Os vestígios constituem-se, pois, em qualquer marca, objeto ou sinal sensível que possa ter relação com o fato investigado. A existência do vestígio pressupõe a existência de um agente provocador (que o causou ou contribuiu para tanto) e de um suporte adequado para a sua ocorrência (local em que o vestígio se materializou)."

Para o novo dicionário da língua Portuguesa - Aurélio Buarque de Holanda Pereira, vestígio é: "Sinal que o homem ou animal deixa com os pés no lugar por onde passa; rastro; pegada; pista..." 
Conclui-se assim - em termos gerais - que os vestígios é o conteúdo material objetivo, capaz de dar base jurídica a um laudo pericial.

O termo indício, encontra-se definido no artigo 239 do Código de Processo Penal: Art. 239 (CPP) - "Considera-se indício a circunstância conhecida e provada, que, tendo relação com o fato, autorize, por indução, concluir-se a existência de outra ou outras circunstâncias".

Segundo o nosso dicionário, a expressão indício sm (lat indício) significam provas circunstanciais e sinais que estabelecem uma relação com o crime, sendo, a partir delas, possível estabelecer hipóteses sobre os culpados ou sobre a maneira como o crime foi cometido. Desta feita, indícios se enquadram como formal da prova material, constituído, subjetivamente, após análise material dos vestígios.

Para o Professor Gilberto Porto: "O vestígio encaminha; o indício aponta"

Apesar de relacionados, tais conceitos podem também gerar equívocos interpretativos. Enquanto o vestígio abrange, a evidência restringe e o indício circunstância.

Para MALLMITH (2007) “os vestígios dão origem às evidências"

ESPÍNDULA (2009) relata que “(...) diante da sensibilidade que representa um local de crime, importante destacar que todo elemento encontrado naquele ambiente é denominado de vestígio, o qual significa todo material bruto que o perito constata no local do crime ou faz parte do conjunto de um exame pericial qualquer, que, somente após examiná-los adequadamente é que poderemos saber se este vestígio está ou não relacionado ao evento periciado. Por essa razão, quando das providências de isolamento e preservação, levadas a efeito pelo primeiro policial, nada poderá ser desconsiderado dentro da área da possível ocorrência do delito.

\section{CONCLUSÃO}

É incontestável a importância do conhecimento criminalístico em todas as esferas da Segurança Pública, bem como a necessidade de regulamentação legal de normas que atendam a necessidade da perícia no Brasil.

Acerca do problema proposto, buscou-se responder o seguinte questionamento: De que modo é possível melhorar a preservação de local de crime de maneira a fornecer mais confiabilidade ao trabalho pericial e atender de forma mais eficiente à sociedade? Com isso, observouse que todo agente recebe uma base teórica de preservação de local de crime, a qual deve ser constantemente abordada devida sua importância. Assim como tornar público este conhecimento, visto que a própria sociedade instintivamente - tende a querer preservar algo que desconhece os limites.

Apesar do agente que faz a preservação de local, receber em sua formação inicial os conhecimentos básicos, em muitos casos, este conhecimento não é aplicado de forma efetiva por uma minimização de alguns crimes, que mesmo constantes no rol taxativo do Código Penal Brasileiro (CPB), acabam, muitas vezes, tratados como "pequenos", como por exemplo o crime de Furto qualificado do artigo $155 \S 4^{\circ}$ I. "com destruição ou rompimento de obstáculo à subtração da coisa". Por este motivo, entende-se que o processo de aprendizagem e aperfeiçoamento do agente deve-se estender no curso de toda sua carreira.

Baseado nesse contexto, conclui-se que a tratativa enfrenta mais problemas relacionados à Políticas Públicas, do que ao empenho dos agentes envolvidos. Este estudo busca motivar todos os órgão que compõe as instâncias formais de controle de crime a avançar numa parceria de comunicação e padronização das atividades, com capacitação de mão de obra adequada e conhecimentos básicos sobre as ciências criminais, bem como, fornecer informações a acerca do fenômeno criminal à sociedade, para que esta ao se deparar com uma cena de crime, não preserve apenas a vítima - como acontece hoje. Dessa forma, o objetivo do Estado de garantir a segurança da prova poderá ter maior efetividade.

É necessário começar a enfrentar as questões de Políticas Criminais com mais seriedade e pés no chão, sabendo que não há um caminho curto para grades mudanças nessa área, contudo, conscientes que melhorias podem acontecer de forma gradativa, assim como acontece em todos os ramos do Direito.

\section{REFERÊNCIAS}

[1] E. Rabelo. Curso de criminalística. 1. Ed. Porto Alegre. Sagra Luzzatto (1996).

[2] C. Kehdy. Elementos da criminalística. 1. Ed. São Paulo. Luzes Gráf. Editora Ltda (1968).

[3] Código de Processo Penal. Decreto Lei no 3.689 (1941).

[4] Código Penal Brasileiro. Decreto Lei no 2.848 (1940).

[5] Constituição da República Federativa do Brasil (1988).

[6] D. M. Mallmith. Local de crime. Porto Alegre. Instituto Geral de Perícias - Departamento de Criminalística (2007). [7] L. E. Dorea. Criminalística. 4. Ed. Campinas. Millennium (2010).

[8] A. Espíndula. Perícia Criminal e Cível. 3. Ed. Campinas, Millennium (2009).

[9] J. A. Velho. Locais de Crime. 1. Ed. Campinas. Millennium (2013).

[10] R.G. Garrido. Ciência Forense: da cena do crime ao laboratório de DNA. 1. Ed. Rio de Janeiro. Projeto Cultural (2014).

[11] G. Da S. Tavares Jr. A Papiloscopia nos locais de Crime: Dactiloscopia, quiroscopia, podoscopia. São Paulo. Ícone (1991).

[12] G.Porto. Manual de Criminalística. 2. Ed. São Paulo. Sugestões Literárias (1969).

[13] E. P. Bittner. Aspectos do Trabalho Policial. São Paulo. Editora Universidade de São Paulo (2003). 
[14] L. G. Marinoni. Prova. São Paulo. Revista dos tribunais (2009).

[15] F. B. De Oliveira. Desafios da Gestão Pública de Segurança. Rio de Janeiro. Editora FGV (2009).

[16] T. M. Garcia / J. C. Régis. Local do crime: a preservação e o isolamento e seus reflexos na persecução criminal. Retirado em 23/10/2018, de http://www.portaldeperiodicos.unisul.br/index.php/U_Fat o_Direito/article/view/3595

[17] T. V. Trufini. Preservando Local de Crime, 2017. Retirado em 16/11/2018, de https://jus.com.br/artigos/56384/preservando-o-local-decrime/

[18] J. De C. Sores. Genética Forense: Local de Crime. 13a Edição no 013 Vol.01. Goiânia. Revista Especialize Online IPOG. Julho (2017). Retirado em 17/11/2018, de https://www.ipog.edu.br/download-arquivosite.sp?arquivo=joilson-de-carvalho-soares-750117.pdf [19] P. F. Ceccaldi. A Criminalística. Europa-América (1962).

[20] Debates. Segurança Pública como tarefa do Estado e da Sociedade. Fundação Konrad-Adenauer-Stifung. E.V.

[21] Portaria $n^{\circ} 82$, de 16 de julho de 2014. Ministério Da Justiça Secretaria Nacional De Segurança Pública. Retirado em 18/12/2018, de http://www.lex.com.br/legis_25740023_portaria_n_82 de 16 de julho de 2014

[22] Projeto Segurança Pública Para o Brasil. Retirado em 19/12/2018, de http://www.dhnet.org.br/redebrasil/executivo/nacional/an exos/pnsp.pdf

[23] F. M. Merotti. Avaliação do conhecimento dos policiais militares recém-formados em relação à preservação do local de crime. Dissertação (Mestrado) Universidade Estadual de Campinas, Faculdade de Odontologia de Piracicaba. SP, 2004. 